\title{
Surgical treatment of bronchial obstruction in primary tuberculosis in children: report of seven cases
}

\author{
A J NAKVI AND H C NOHL-OSER
}

From the Cardiothoracic Unit, Harefield Hospital, Harefield, Middlesex, UK

ABSTRACT Seven children, aged 4 months to 10 years, with bronchial compression due to tuberculous hilar lymphadenitis have been treated surgically since 1974. The indications for surgical treatment were lack of response to chemotherapy and in particular the development of respiratory distress. Excision or curettage of the affected nodes was found to be a safe and sure method of relieving the acute symptoms and preventing permanent damage to the lung.

Gross enlargement of the hilar lymph nodes can be the dominant feature of primary tuberculosis in some children (Macpherson and Lutwyche, 1950). This may result in bronchial obstruction caused either by external compression or through erosion of the bronchus where granulation tissue or caseous material or both actually block the lumen of the bronchus. The small diameter of the bronchi in children and their lack of rigidity makes them specially liable to become obstructed (Krzhivitskaya et al, 1967). Segmental or lobar collapse is, therefore, a relatively common complication of primary tuberculosis, while obstructive emphysema resulting from partial obstruction is relatively rare (Singh and Richards, 1957). The great majority of these children respond to chemotherapy, but there are exceptional cases where no improvment is noted after several months of treatment. In some of these respiratory distress can develop as a result of bronchial obstruction, and surgical treatment, which at times may be urgent, is then indicated (Chesterman, 1957; Nohl and Steele, 1960). We report our experience of seven such cases, which have been treated in our unit over the past seven years.

\section{Case 1}

A 12-month-old girl had been treated with various courses of antibiotics for upper respiratory tract infection with minimal response. Her chest radiograph showed gross hilar lymphadenopathy (fig 1a). The Mantoux test was strongly positive. Antituberculosis treatment was started with rifampicin, $150 \mathrm{mg}$ daily $(12 \mathrm{mg} / \mathrm{kg})$, ethambutol,

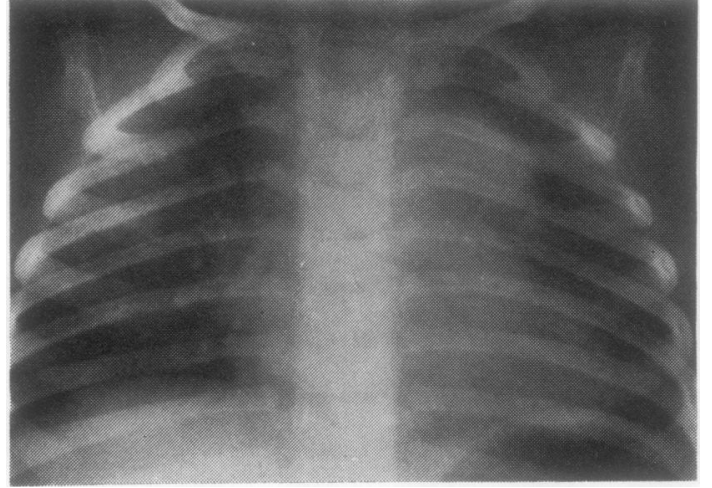

Fig 1a Case 1. Chest radiograph showing paratracheal mass.

$150 \mathrm{mg}$ daily $(12 \mathrm{mg} / \mathrm{kg})$, and INAH, $100 \mathrm{mg}$ daily $(8 \mathrm{mg} / \mathrm{kg})$. After six weeks of treatment she became very wheezy, and the chest radiograph showed a left upper lobe collapse in addition to the enlarged hilar nodes.

At bronchoscopy the left main bronchus was blocked partly by a submucosal swelling and partly by granulation tissue. A perforation through which caseous material was discharging was also found at the origin of the bronchus. Although aspiration of this material seemed to result in an adequate lumen, neither clinical nor radiological improvement followed (fig 1b). A thoracotomy was advised. At operation, on 1 March 1974, the subaortic nodes at the origin of the left main bronchus were found to be severely diseased. The nodes between the lingular and lower lobe bronchi 


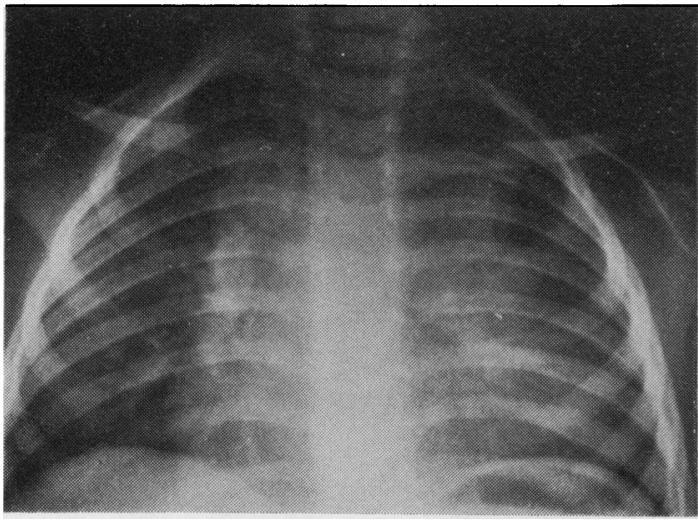

Fig 1b Case 1. Seven weeks later the mass is unchanged. There is collapse and consolidation in left upper lobe.

were also affected. In addition there was massive nodular disease of the apical segment of the left upper lobe. Removal of the diseased nodes resulted in full expansion of the upper lobe. Postoperative progress was satisfactory. A chest radiograph three years later showed no evidence of disease.

\section{Case 2}

A girl, aged 4 months (weight $4.6 \mathrm{~kg}$ ), presented with severe dyspnoea and a dry cough. Her chest radiograph suggested a right upper lobe pneumonia. She was treated at first with ampicillin, which was changed to sodium aminosalicylate (Pasinah-D), $10 \mathrm{ml}$, and streptomycin, $125 \mathrm{mg}$ daily, when her sputum was found to be positive for tubercle bacilli. The Heaf test was negative at first, but became strongly positive six days later. Her condition deteriorated, and a further radiograph showed a right upper lobe collapse with obstructive emphysema of the middle and lower lobes and enlarged hilar nodes (fig 2a). Over the next two months, while on antituberculosis treatment, she improved clinically but a chest radiograph remained unchanged. At bronchoscopy the right intermediate bronchus was distorted by a bulge in the medial wall. It was decided to continue with conservative treatment; a few days later, however, the right middle and lower lobes became grossly distended (fig 2b). On 22 May 1974 a right thoracotomy was performed, and a large inflamed node was removed from between the lower lobe bronchus and the oesophagus. Curettage of this area showed a hole in the posterior wall of the bronchus, which was closed. Other necrotic nodes between the branches of the lower lobe bronchus were excised. Her condition

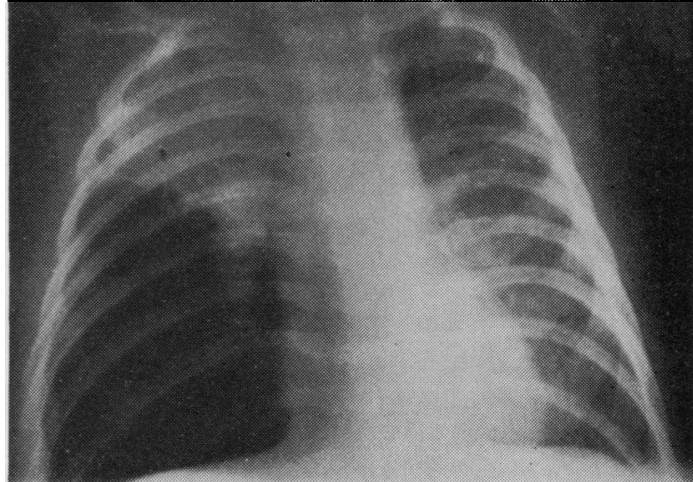

Fig 2a Case 2. Collapse and consolidation in right upper lobe with right hilar gland enlargement and obstructive emphysema of middle and lower lobes.

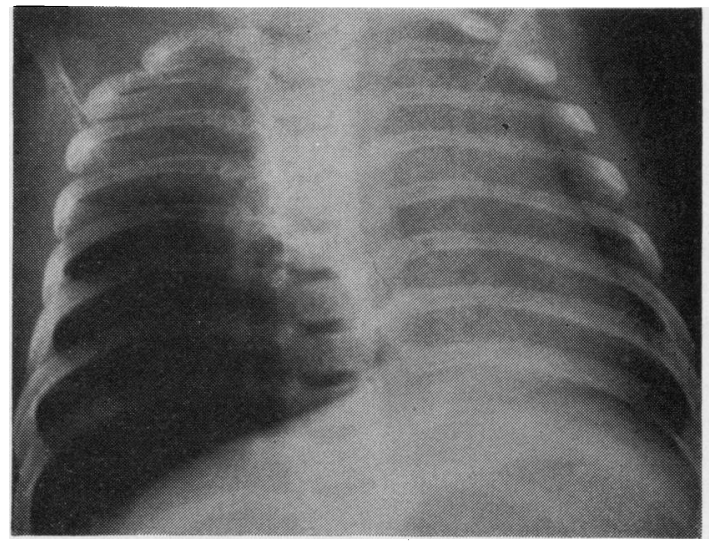

Fig 2b Case 2. Six weeks later. Right upper lobe collapse and grossly overexpanded right middle and lower lobes. Heart is displaced into left chest.

rapidly improved. A chest radiograph three years later showed no evidence of disease.

\section{Case 3}

A girl, aged 14 months, presented with a threeweek history of a wheezy cough. Her father had been treated for pulmonary tuberculosis. A chest radiograph showed a right upper lobe collapse and right paratracheal lymphadenopathy. She was given a course of ampicillin and cloxacillin with minimal response. Antituberculosis chemotherapy was started when gastric washings were found to be positive for acid-fast bacilli. After three months of treatment with INAH, $75 \mathrm{mg}$ twice daily $(15 \mathrm{mg} / \mathrm{kg})$, rifampicin, $100 \mathrm{mg}$ twice daily $(20$ $\mathrm{mg} / \mathrm{kg}$ ), and ethambutol, $250 \mathrm{mg}$ daily $(25 \mathrm{mg} /$ $\mathrm{kg}$ ), she developed an inspiratory stridor that 
became severe whenever she cried. Bronchoscopy on 17 June 1977 showed a bulge in the right lateral wall of the trachea, which narrowed the lumen to half its normal size. The right main bronchus became totally obstructed during inspiration. The child developed severe respiratory obstruction after the bronchoscopy, and an emergency thoracotomy had to be carried out on the same day. A large caseating superior tracheobronchial node was excised, which resulted in full expansion of the previously atelectatic anterior segment of the right upper lobe. Soon after operation, however, severe stridor recurred with intercostal recession, mainly on the right side. She was ventilated mechanically for 24 hours. Thereafter, her recovery was satisfactory, and she is now well.

\section{Case 4}

A 2-year-old boy was found to be tuberculin positive when investigated as a contact of his father who had pulmonary tuberculosis. Two months earlier he had been investigated for anaemia, which necessitated a blood transfusion. His chest radiograph showed shadowing in the right upper lobe and a right paratracheal mass, which did not become smaller over the next 16 months, despite a course of streptomycin, $250 \mathrm{mg}$ daily $(20 \mathrm{mg} / \mathrm{kg})$, PAS, $1 \mathrm{~g}$ twice daily $(150 \mathrm{mg} / \mathrm{kg})$, and INAH, $50 \mathrm{mg}$ twice daily $(8 \mathrm{mg} / \mathrm{kg})$. Bronchoscopy showed caseous material at the right tracheobronchial angle. At thoracotomy on 14 July 1970 a mass of tuberculous nodes was present in the tracheobronchial angle. One of these had perforated into the bronchial lumen. The lung was adherent to the nodes and concerned in the disease process. An adenectomy was performed and the perforation closed. He improved satisfactorily both clinically and radiologically, and he is now well.

\section{Case 5}

A 3-year-old boy, who had been in contact with a case of tuberculosis, developed loss of appetite, dyspnoea on exertion, and a dry cough. His chest radiograph showed enlarged right paratracheal nodes (fig 3a). Acid-fast bacilli were present in the sputum. He was given streptomycin, $250 \mathrm{mg}$ daily (20 mg/kg), rifampicin, $225 \mathrm{mg}$ daily $(20 \mathrm{mg} / \mathrm{kg})$, and INAH, $150 \mathrm{mg}$ daily $(12 \mathrm{mg} / \mathrm{kg})$, but over the next 12 months, despite improvement in his general condition, serial chest radiographs showed progressive enlargement of the paratracheal nodes (fig 3b). At bronchoscopy the trachea was indented from the right side and the right main bronchus was compressed. In view of these findings and the failure of medical treatment right thoracotomy was performed on 19 August 1974. Enlarged caseous paratracheal and superior tracheobronchial nodes were excised. Recovery was uneventful. He has remained well (fig 3c).

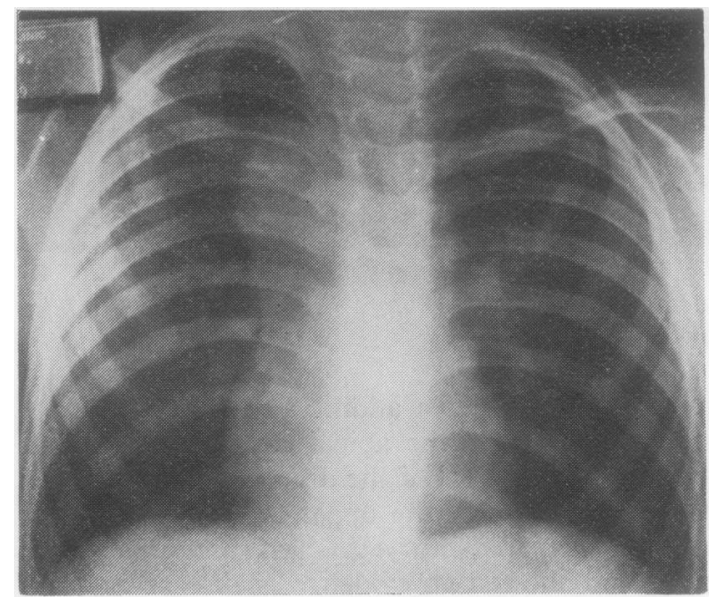

Fig. 3a Case 5. Chest radiograph showing right paratracheal mass.

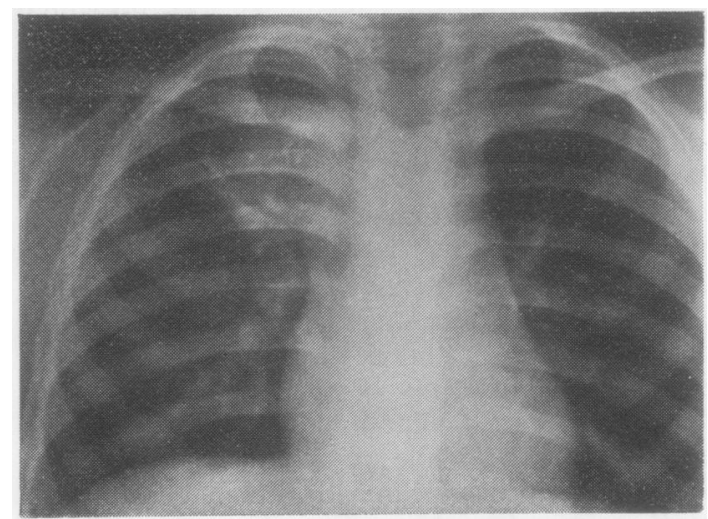

Fig 3b Case 5. Eight months later lymph node mass is more prominent. There is some shadowing extending into right upper lobe.

Case 6

A girl, aged 2 years, who had been receiving streptomycin, $400 \mathrm{mg}$ daily $(25 \mathrm{mg} / \mathrm{kg})$, ethambutol, $150 \mathrm{mg}$ daily $(9 \mathrm{mg} / \mathrm{kg})$, and INAH, $100 \mathrm{mg}$ daily $(6 \mathrm{mg} / \mathrm{kg})$, for two months for tuberculous meningitis, developed obstructive emphysema of the left lung from enlarged hilar glands. Broncho- 


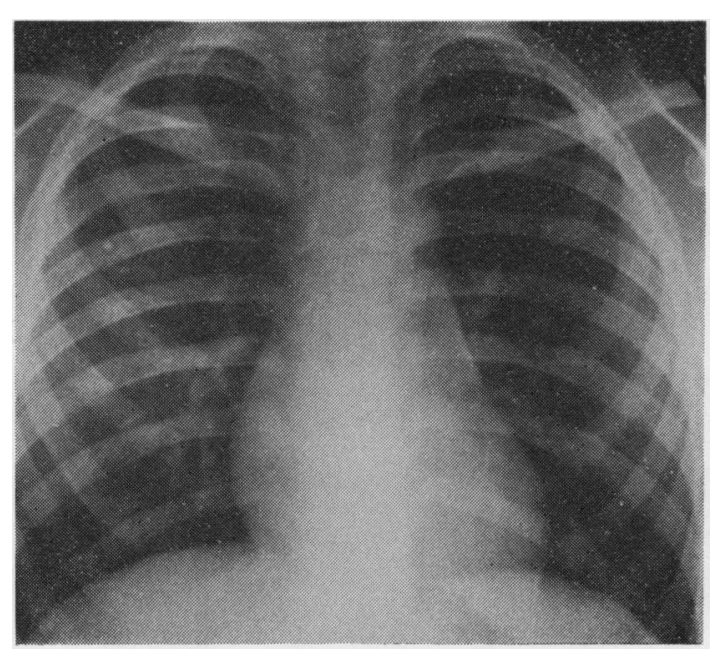

Fig 3c Case 5. Four years after operation there is no evidence of active disease.

scopy showed that the left main bronchus was obstructed at its origin by a perforating node on the lateral wall. At operation on 13 June 1972 necrotic material was evacuated from enlarged paraphrenic nodes, and the caseous subaortic nodes were excised, which relieved the obstruction. The perforation in the main bronchus was closed. Recovery was uneventful. She has remained well, and there is no evidence of disease on a recent chest radiograph.

\section{Case 7}

A 10-year-old girl was admitted with a history of cough and fever. She was underweight and the breath sounds on the right side of her chest were considerably diminished. A chest radiograph showed right paratracheal lymphadenopathy and a shadow radiating from the right hilum into the anterior segment of the right upper lobe. The Mantoux test was strongly positive. At bronchoscopy the right main bronchus was inflamed and the lower lobe bronchus grossly deformed with very oedematous mucosa. Antituberculosis chemotherapy was started with streptomycin, $0.5 \mathrm{~g}$ daily $(20 \mathrm{mg} / \mathrm{kg})$, INAH, $100 \mathrm{mg}$ twice daily $(8 \mathrm{mg} / \mathrm{kg})$, and PAS, $1 \mathrm{~g}$ twice daily $(80 \mathrm{mg} / \mathrm{kg})$. Five months later her chest radiograph showed a right upper lobe collapse and bronchoscopy now showed caseous material in the upper lobe bronchus, which had been perforated by a node. In view of these findings a right thoracotomy was performed on 18 April 1972. Large caseous nodes were present in the superior tracheobronchial angle and one of these had perforated into the anterior segmental bronchus of the upper lobe. An adenectomy was carried out, and the perforation was closed. The postoperative period was uneventful, and she has remained well.

All seven patients received antituberculosis chemotherapy for at least six months after operation.

\section{Discussion}

The small number of cases presented here and the lack of similar reports in the past decade are evidence of the successful management of tuberculosis today. In Britain areas with a high immigrant population remain the source of a relatively small number of new cases of primary tuberculosis (British Thoracic and Tuberculosis Association, 1975; Prowse and Cavanagh, 1976; British Medical Journal, 1977).

Hilar adenitis is a prominent feature in primary tuberculosis, especially in children. In most cases both lymphadenitis and parenchymal involvement resolve with medical treatment (Adler and Richards, 1953; Bentley et al, 1954). In children, because of the lack of rigidity and small diameter of the bronchi, complications may arise when the hilar lymph nodes show gross enlargement. Pressure by enlarged nodes may cause partial or complete obstruction of a primary or secondary bronchus, resulting in segmental collapse or obstructive emphysema or both of one or more lobes. Secondary infection of an atelectatic segment may result in permanent bronchiectasis even when the obstruction has subsided (Hiltz et al, 1963). Clinically, bronchial compression may be shown by wheezy respiration, dry cough, or stridor.

When the caseous contents of a node rupture into a bronchus, the corresponding segment of the lung may either become atelectatic or tuberculous pneumonia may develop. Asphyxia, from extrusion of a large amount of caseous material, is extremely rare but has been reported (Vosschulte, 1951; Bentley et al, 1954). Usually, the discharge is intermittent through a small hole in the bronchus.

Segmental lesions usually resolve satisfactorily in response to adequate antituberculosis chemotherapy (Thomas, 1952), yet the incidence of residual bronchial abnormalities has been reported to be as high as $55 \%$ (Hutchison, 1951; Valledor and Navarette, 1952; Williams and Anderson, 1953). Most of these children, however, remain asymptomatic (Macpherson and Lutwyche, 1950; Bentley et al, 1954; Cameron 
et al, 1957). The enlarged lymph nodes on the other hand may not diminish in size despite several months of drug treatment, and segmental collapse in such patients may not resolve. Corticosteroids in the treatment of the primary complex have been generally unimpressive. The glandular component usually seems to be unaffected, probably because caseation has already occurred. Steroid treatment is indicated in very ill patients, except in the very young where there is a danger of pneumothorax (Gerbeaux et al, 1965). All the seven children we report were treated with a combination of three antituberculosis drugs for periods ranging between two and 16 months before operation. None of them received steroids.

When bronchial obstruction is suspected, bronchoscopy is necessary to assess the nature and extent of bronchial involvement. The aspiration of caseous material or mucopus may relieve the obstruction. Surgical removal of the enlarged nodes is indicated when there is evidence of respiratory obstruction, obstructive emphysema, or perforation. When there is no response to drug treatment, operation may be necessary to prevent irreversible lung damage (Huish, 1956). With chemotherapeutic cover this operation can be carried out with a low risk of complications. The close relation of the nodes to the pulmonary vessels, superior vena cava, and the aorta, and the presence of dense adhesions, can make excision technically difficult and hazardous. In these cases it is safer to incise the capsule of the node and evacuate its contents (Thomas, 1952; Nohl and Steele, 1960; Ertli and Slontchak, 1966). If a hole in the bronchial wall is seen it should be closed. A badly damaged segment of the lung or lobe may be removed at the same time. Respiratory distress developing or persisting after adenectomy is an unusual complication, which has not been described before. Although laryngeal oedema from intubation is not uncommon in infants, in case 3 it was excluded since on reintubation there was no evidence of it. Postoperative respiratory distress in this case was assumed to have been caused by persistent obstruction of the right main bronchus because of either mucosal oedema or paradoxical movement of the bronchial wall after removal of the large gland which left an unsupported area.

Indications for surgical treatment in our patients included respiratory obstruction in case 3 , obstructive emphysema in case 2 , and perforation and persistent segmental or lobular collapse in cases $1,4,6$, and 7 . One child, case 5, had drug treatment for 12 months without diminution in the size of the glandular complex. The results of surgical treatment in these children were of immediate and striking benefit.

We thank Miss $M \quad P$ Shepherd, consultant thoracic surgeon, for permission to report case 2 .

\section{References}

Adler, D, and Richards, W F (1953). Consolidation in primary pulmonary tuberculosis. Thorax, 8, 223241.

Bentley, F J, Grzybowski, S, and Benjamin, B (1954). Tuberculosis in Childhood and Adolescence. NAPT, London.

British Medical Journal (1977). Screening for tuberculosis. 2, 538.

British Thoracic and Tuberculosis Association (1975) Tuberculosis among immigrants related to length of residence in England and Wales. British Medical Journal, 3, 698-699.

Cameron, J K, Hay, J D, and Temple, L J (1957). A critical examination of the role of surgery in the treatment of primary pulmonary tuberculosis in children. Thorax, 12, 329-337.

Chesterman, J T (1957). The surgery of primary pulmonary tuberculosis in children. Thorax, 12, 159 163.

Ertli, A A, and Slontchak, A T (1966). Features peculiar to surgical interventions in tuberculosis of intrathoracic lymph nodes and its complications. Problemy Tuberkuleza, 44, No 8, 21-26.

Gerbeaux, J, Baculard, A, and Couvreur, J (1965). Primary tuberculosis in childhood. Indications and contraindications for corticosteroid therapy; observations on 577 treated cases. American Journal of Diseases of Childhood, 110, 507-519.

Hiltz, J E, MacRae, D M, and Quinlan, J J (1963). The ulcerating tuberculous hilar gland. Canadian Medical Association Journal, 89, 193-197.

Huish, D W (1956). The surgical treatment of pulmonary tuberculosis in childhood and adolescence. Thorax, 11, 186-200.

Hutchison, J H (1951). Post-tuberculous bronchiectasis in children. Tubercle, 32, 271-278.

Krzhivitskaya, V P, Ivanovskaya, $T \mathbf{M}$, and Nechayeva, T I (1967). Atelectasis as complication of bronchoglandular tuberculosis. Klinicheskaya Medicina, 14, No 12, 69-72.

Macpherson, A M, and Lutwyche, V U (1950). Collapse of the lung associated with primary tuberculous lesion. Thorax, 5, 1-4.

Nohl, H C, and Steel, S J (1960). Surgical treatment of pulmonary tuberculosis in childhood. British Journal of Diseases of the Chest, 54, 255-264.

Prowse, R, and Cavanagh, P (1976). Tuberculosis in the potteries 1971-1974. Lancet, 2, 357-359.

Singh, D, and Richards, W F (1957). Obstructive emphysema in primary pulmonary tuberculosis. Tubercle, 38, 397-402.

Thomas, D (1952). Discussion on the fate of the tuberculous primary complex. Proceedings of the Royal Society of Medicine, 45, 743-745. 
Valledor, T, and Navarette, A (1952). Bronchiectasis in childhood and adult pulmonary tuberculosis. Diseases of the Chest, 22, 46-53.

Vosschulte, K (1951). Uber die Exstirpation tuberkulöser Mediastinaldrüsen bei drohendem Bronchusdurchbruch. Chirurg, 22, 310-314.

Williams, H, and Anderson, C (1953). Bronchiectasis and bronchostenosis following primary tuberculosis in infancy and childhood. Quarterly Journal of Medicine, 22, 295-308.

Requests for reprints to: Mr A J Nakvi, Cardiothoracic Unit, Harefield Hospital, Harefield, Middlesex. 